Resumen: Introducimos a nuestros estudiantes a la comunicación visual en arquitectura entendiendo esa inicialidad en la especificidad de la disciplina. Reflexionamos desde una existencia alimentada de una visualidad que nos organiza permanentemente los modos de vida e interacción con el medio. Un nuevo sistema de lo visible demandado por la virtualidad reacondiciona las lógicas de comprensión y análisis del mundo instalándose como una nueva forma de ver y de relacionar nuestra mirada con nuestras acciones. La propuesta de cátedra fue articular esta nueva visibilidad en el ciclo 2020. Nos demandó análisis, exploración y revisión entre saberes diferentes, pero no contrapuestos. Elegimos accionar y nos sorprendió el saber.

Palabras clave: Comunicación - visualidad - articulación - codificación - virtualidad.

[Resúmenes en inglés y portugués en la página 100]

(1) Arquitecta, Especialista en Docencia Universitaria, (UNMDP). Directora de proyecto de investigación en didáctica proyectual. Profesora adjunta Introducción a la Comunicación Visual (FAUD). Facultad de Arquitectura, Urbanismo y Diseño de Mar del Plata. Integrante del Centro de Investigaciones Proyectuales y Acciones de Diseño Industrial (CIPADI).

(2) Arquitecto, Especialista en Gestión Integral del Proyecto Arquitectónico y Urbano. Docente Taller Vertical de Diseño Arquitectonico FAUD. (FAUD UNMDP) Asesor y Miembro del Cuerpo de Jurados del CAPBA Distrito IX.

\title{
La expansión
}

"Del saber también es propia su negatividad, en la medida que no rara vez, tiene que conquistarse luchando contra una resistencia”. (Han, 2015, p22). Cuando diseñamos una propuesta pedagógica involucramos siempre una estructura propositiva que no deja de ser una promesa, un ofrecimiento que manifestamos con un determinado objetivo a al- 
canzar. Es desde ese objetivo desde el que esperamos una acción o una respuesta por parte de a quien esté dirigida. Pero básicamente toda propuesta tiene siempre como punto de partida un diagnóstico de situación, una base desde la que se justifica y se asienta para el cumplimiento de sus objetivos.

Cuando hablamos con nuestros estudiantes de introducirlos a la comunicación visual en arquitectura, aclarándoles siempre que se comprende esa inicialidad en el contexto de la especificidad de la disciplina, explicamos que nuestra existencia se alimenta permanentemente de una visualidad que organiza los modos de vida e interacción en el medio cultural que nos rodea. La re-significación de ese régimen de visibilidad en el contexto del aprendizaje del mensaje arquitectónico, haciéndolo funcional a un modo codificado de la comunicación visual fue nuestra tarea a lo largo de los años en el ciclo introductorio de la carrera de Arquitectura. La constitución de un nuevo sistema de lo visible demandado por la virtualidad en el ciclo 2020, reacondiciona las lógicas de comprensión y análisis del mundo. Desde las redes de información, comunicación y contacto nos instalamos en una nueva forma de ver y de relacionar nuestra mirada con nuestras acciones.

La propuesta de la cátedra fue la de articular esta nueva visibilidad durante el desarrollo académico, proceso que demandó de análisis, exploración, reconocimiento y articulación entre saberes diferentes, pero no contrapuestos. Es desde esta perspectiva que se implementó la reformulación de la dinámica pedagógica de nuestra asignatura, inmersa en el nuevo régimen de visibilidad en pandemia, régimen demandado por una operatoria de completa virtualidad en el contexto del aprendizaje del mensaje comunicacional arquitectónico. Es sustancial inicialmente repasar y examinar brevemente algunos hitos de nuestra historia académica, como premisa para entonces desde allí posicionar y justificar los nuevos desarrollos propositivos implementados en la etapa de virtualidad completa 2020.

\section{La Génesis}

El contexto de enseñanza en el que nos vimos inmersos desde el 2020 como educadores está determinado por tres campos de problematización que caracterizan sin lugar a duda condiciones de pensamiento y formación que ya incorporamos con claridad en la actualidad: la ruptura de los modelos lineales, los patrones de simultaneidad y la temporalidad de la inmediatez. Cuando Inés Moisset (2003) presentó este paradigma como el mundo de las relaciones múltiples ya nuestra incorporación de las redes sociales como parte de la propuesta pedagógica tenía un objetivo inicial: amplificar a partir de esa nueva conceptualización del mundo el intercambio productivo del taller, en la construcción de un aprendizaje significativo y motivador desde esas nuevas perspectivas.

Comenzamos utilizando las redes sociales disponibles con el objetivo de poder compartir la producción de nuestros estudiantes entre sí, intentando mejorar la interrelación entre distintos grupos dentro de la cátedra, sin embargo, este intercambio evolucionó en capas que desconocíamos. Dos aspectos se revalorizaron a partir de ese momento: uno el motivacional: estudiantes con poca participación en el taller presencial, se posicionaron 
como muy activos en las redes, se comenzaron a emplear los comentarios como estrategias de intervención y opinión sobre trabajos de compañeros, así como aportes ante dudas o complicaciones con avances y/o consignas. El otro aspecto fue conceptual: el enfoque que presentaba la pantalla en lo que se estaba observando potenciaba la capacidad de asimilar y dar valor al producto del otro para luego habilitar a un proceso de reflexión y desarrollo del trabajo propio. Iniciamos entonces un proceso de revalorización de este intercambio incorporando archivos y contenido multimedia en formato de tutoriales o tips para el desarrollo de actividades específicas, en paralelo a las clases teóricas y/o del taller presencial. Esta estrategia definió la construcción paulatina de un taller híbrido (mediando entre lo analógico y lo digital) sostenido en la decisión de articular ambos espacios como sitios de aprendizaje con modalidades constructivas diferentes y encauzados en la formación profesional que la misma unidad académica profundizaba con la incorporación y ampliación paulatina de infraestructura digital acorde a los espacios y recursos académicos disponibles al momento. De este modo el laboratorio de informática fue el primer gran paso para acercar a los estudiantes sin estos recursos, la posibilidad de conectarse a las redes y poder utilizar herramientas digitales específicas. Otro proceso evolutivo importante en la revalorización de las redes como espacio de aprendizaje nos lo dieron las nuevas crisis económicas, con la imposibilidad en el caso de muchos de nuestros estudiantes de la impresión completa de sus paneles. Esta situación reposicionó el espacio de Facebook como un sitio de entrega virtual que también nos permitió abordar otro objetivo: habilitar un sistema de autoevaluación en base a pautas dadas de revisión para producciones propias y ajenas, potenciando el recorrido sobre las producciones que sus compañeros publicaban paulatinamente dentro de álbumes abiertos para los estudiantes a tal efecto. Se conformó así una nueva modalidad de evaluación mediada por la revisión crítica de lo elaborado y contemplando una comparativa real sobre la totalidad de lo generado en el taller con dos instancias de evaluación diferidas temporalmente. La segunda entrega se enlazó con el taller presencial complementandose con pruebas de impresión sobre sectores específicos de los paneles, de modo de poder establecer criterios de legibilidad, imagen, contraste, etc. sobre el producto morfológico y el mensaje terminado.

\section{Las preguntas}

Pero los educadores somos el habitar de las preguntas: ¿Cómo aprendemos? ¿Cuándo sucede? ¿Fuimos conscientes? ¿Importa serlo? Son preguntan casi diarias en la tarea docente como aprendices permanentes que somos y presentes además en un momento en donde el saber y la información parecieran difuminar límites y simultáneamente también nuestros habitares. Son entonces estas también las preguntas que guiaron nuestros caminos. Porque cada reflexión conceptual está ineludiblemente sostenida en un reposicionamiento permanente como docente y como estudiante, recurriendo siempre a una praxis particular, aquella construida desde ese otro conocimiento, el que deviene de las propias dinámicas, de los datos, las vivencias y las posibilidades de aplicación de las ideas pedagógicas en el 
quehacer cotidiano de la enseñanza. Es una tarea de concepción signada por un tiempo en el que en nuestras aulas experimentamos cada día y con más intensidad esa dicotomía creciente entre la construcción del saber y la saturación de información. En ese sentido el filósofo Byung- Chul Han, reflexiona desde esta situación, muy pertinente para nosotros los educadores, desde un lugar poco común: el tiempo. Afirma que:

El saber tiene una estructura temporal por completo distinta al flujo de la información mediática. Mientras el saber se tensa entre pasado y futuro. La información por el contrario habita un tiempo que se ha satinado a partir de puntos de un presente indiferenciado. Es un tiempo sin acontecimientos ni destino (Han, 2015, p. 22).

Como educadores se hace evidente la conciencia de trabajar desde la formación superior en la producción de un conocimiento que siempre nos debe acontecer. Pero ese saber situado se debe definir siempre en su apropiación a la sociedad, en un espacio- tiempo real del que nos debemos hacer responsables como personas y como parte de una institución cuya función primera es la de formar ciudadanos conscientes, reflexivos y productivos a esa sociedad. Es a ese modo de aprender, al que podemos llamar "encuentro "al que se adscribe desde esta propuesta a partir de cada razonamiento, desarrollo y didáctica propuesta. ... "no hay alguien que sabe y otro que ignora. Todos aprendemos a un mismo tiempo, componiendo problemas en conjunto, en situaciones que puede llamárseles "encuentros". Y esto es válido para cualquier otro ámbito. Mucha generosidad y apertura son imprescindibles para que este acontecimiento sea convocado, intentado, siquiera concebido. Un maestro ha de ser alguien en tensión con uno mismo, con lo que sabe o cree saber, con su propia biología y no sólo la intelectual" (Pablo Sztulwark 2015, p.21).

\section{Un camino estratégico}

Es signo de la disciplina la singularidad e impredecibilidad propia que signan el contexto de la enseñanza proyectual, tal como advierte Litwin (2007). Abrevar en este nuevo paradigma nos posiciona en un propósito formativo sostenido en la idea de camino estratégico que propone Edgar Morín (2003) entendido como un ensayo de estrategias para responder a las incertidumbres. El ciclo 2020 fue sin lugar a duda un tiempo que requirió estar dispuestos a responder a la confusión y perplejidad que demandó lo denominado como nueva normalidad. Creemos que es a partir de esta experiencia que podemos reflexionar acerca del camino transitado, de cómo redefinimos nuestra propuesta académica desde el lugar instalados en una nueva forma de ver y de relacionar nuestra mirada con nuestras acciones pedagógicas. En primer lugar, definimos el nuevo espacio del taller virtual total como un lugar de ensayos, conjeturas y razonamientos, pero al mismo tiempo de concreciones. Este marco de acción, lo dará una característica fundamental para el desarrollo 
didáctico propuesto que se puede inscribir dentro de lo que se denomina "pensamiento complejo" (Morin, 2003, p 35) entendiéndolo como una modalidad de aproximación al saber que integra tanto lo racional y lo objetivo como los aspectos sensibles del sujeto. Propiciar un tejido en conjunto, de allí que el pensamiento complejo, en palabras del propio Morín, se base en establecer relaciones y complementos en el estudio del todo tomando en cuenta la reciprocidad que tiene lugar entre éste y sus partes. Este concepto promueve el holístico, aunque sin abandonar la noción de las partes constituyentes del todo. La complejidad representa la realidad en la que nos movemos como una gran red de finos hilos que se entrelazan y que relacionan todos sus componentes. Nos reconformamos y readaptamos sobre una base eminentemente dinámica, de fluctuación y conflicto permanente a lo largo de todo el ciclo y sin lugar a duda las particularidades y la diversidad de la población académica fue un punto determinante para abordar las estrategias del grupo ingresante, con modos de aprendizaje y de acercamiento a los procesos educativos muy diferentes y con lazos a la virtualidad y la connivencia digital absolutamente disímiles.

\section{Campos de problematización}

Se identificaron tres campos de problematización que enmarcaron nuestras acciones. Desde allí se definieron los aportes conceptuales que bajo una modalidad operativa y estratégica posibilitaron llevar adelante la propuesta académica de la asignatura en el ciclo de virtualidad completa.

El campo contextual, que se redefinió en la nueva normalidad de pandemia dejando al descubierto más explícitamente al complejo entramado del que la Educación Pública es resultado directo como construcción física y simbólica. Los ejes propositivos de trabajo desde este campo fueron dos: la atención a la diversidad y la disminución/ nivelación de la brecha digital. El campo epistemológico, como el lugar de las decisiones que surgen como emergentes a las singularidades propias de la disciplina y que se sostiene en la construcción de un conocimiento imbricado en la acción proyectual. El eje propositivo de este campo fue: espacializar, sostener desde todas las dinámicas la construcción de un pensamiento orientado a la producción de respuestas coherentes y efectivas a la resolución de situaciones problemáticas vinculadas al pensamiento y comunicación de las formas en el espacio. El campo pedagógico, desde donde se resignificó una praxis generadora de conocimientos como devenir de procesos de experimentación e investigación con una modalidad de acción orientada a la actualización y revisión de acciones permanente. Fueron dos los ejes propositivos en este campo: la revisión crítica y las explicaciones conceptuales entre pares. 


\section{Dinámicas de abordaje}

\section{De lo lúdico a la búsqueda experimental}

La premisa del abordaje inicial con nuestros estudiantes lo definimos desde el lugar de la exploración y la búsqueda entendiéndola como el recorrido por lugares desconocidos o poco conocidos para abordarlos y descubrir lo que proponemos que encuentren en ellos. Nuestros espacios de taller virtual estuvieron conformados en el ciclo 2020 por: la página de Fb. de la cátedra, el Blog de cátedra, el Aula Virtual Campus Académico FAUD, el Instagram de cátedra. La estrategia planteada para el inicio de la actividad fue un modelo lúdico: Búsqueda del tesoro y Collage Colaborativo. En ambas estrategias el objetivo principal se orientó a que los estudiantes llegarán rápidamente a apropiarse de esos espacios virtuales para obtener y extraer desde allí elementos necesarios para usarlos y aprovecharlos en una tarea específica. (Fig. 1 La búsqueda del tesoro).

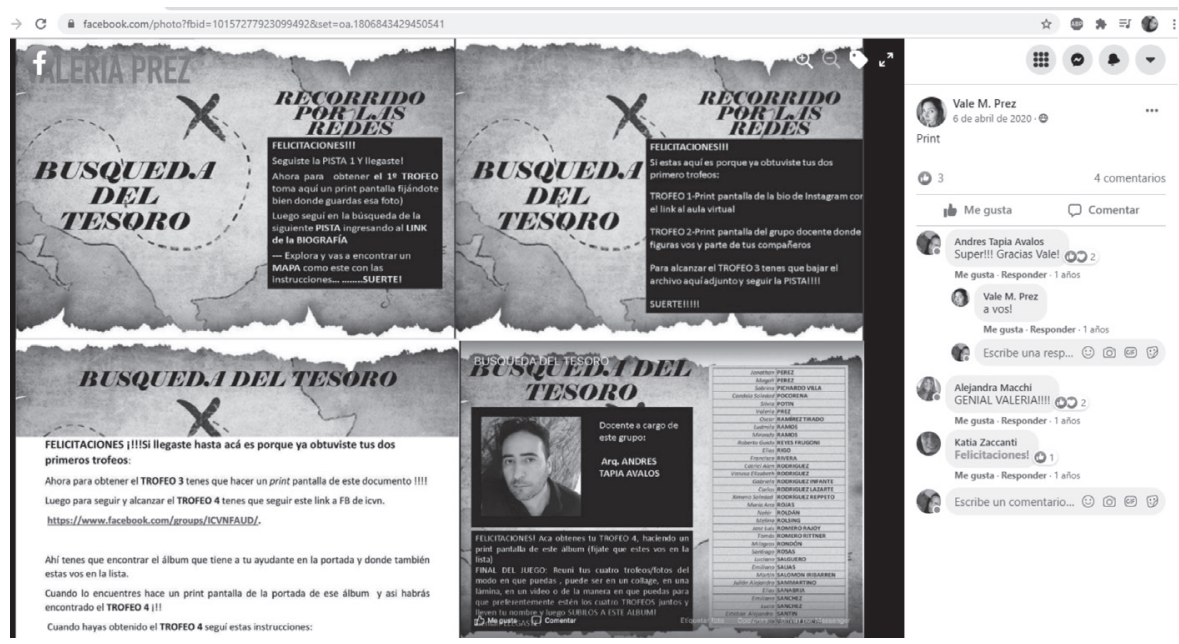

Fig. 1. Lo lúdico/ Búsqueda del tesoro. / Fuente propia/producción de cátedra ciclo 2020.

Mientras que la búsqueda del tesoro se determinó como la acción o movimiento individual del estudiante en las redes, poniendo en juego la posibilidad o no de alcanzar la meta/ objeto como captura de un elemento estratégico entretejido en la virtualidad de cada espacio de red, el Collage Colaborativo se propuso como una instancia de cooperación activa entre pares. Este último se definió, así como parte de las acciones colectivas que buscan alcanzar objetivos de aprendizaje comunes: una intervención comunicacional donde las 
partes individuales se unen y organizan entre sí para conformar un todo y cuyo impacto será mayor que la suma de los elementos intervinientes. (Fig. 2 Collage Colaborativo). Como actividad dividida en tres etapas, se incentivó la primera como instancia particular del pensamiento a partir de imágenes incompletas de arquitectura: la modalidad fue el completamiento a partir del dibujo de modo excluyente/analógico o digital/ lo que dio paso luego a compartirlo con su grupo en la red .La elección colectiva de una frase motivadora inició un proceso de asociación y reinterpretación de las imágenes intervenidas en un nuevo sentido comunicacional, ahora definido por el grupo y transformado a través de las herramientas digitales disponibles.
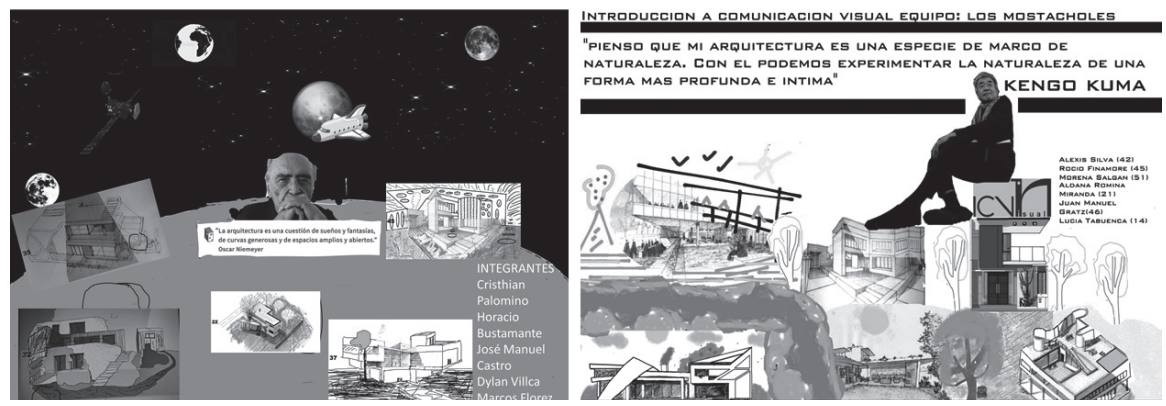

Fig2 Lo lúdico/Collage Colaborativo/ Fuente propia, producción de estudiantes ciclo 2020

Se trabajó aquí desde dos momentos que involucran un proceso creativo y que buscamos mantener en la revisión de nuestras diferentes actividades a lo largo de todo el ciclo virtual: Un primer momento que conduce al descubrimiento, favoreciendo el desarrollo de la imaginación en la explotación de diferentes posibilidades, ideas y sentimientos y que produce en consecuencia respuestas y soluciones disímiles. Un segundo momento como manifestación frente al otro, que favorece la búsqueda de diferentes lenguajes dentro del enorme abanico que ofrece la intencionalidad comunicativa. Esta idea de apropiación y utilidad con una finalidad cierta combinado a una estructura de juego fue convocante y nos permitió capturar además de la atención de nuestros estudiantes un modo fluido de vincularse con espacios virtuales de trabajo que hasta el momento les eran ajenos. Otro objetivo a cubrir con estas primeras dinámicas se orientaba a aportar una primera nivelación digital y de información básica con relación a recursos disponibles por los estudiantes, necesaria como estrategia para el inicio de una actividad de modo completamente remoto como la que se presentaba por delante. 


\section{Una ventana de apertura a la clase}

Si bien las clases virtuales siguieron un cronograma diario igual al desarrollado en la presencialidad la falta de recursos disponibles o de conexión segura de muchos de los estudiantes en el momento y horario estipulado, además de la desorientación propia de la cantidad y variedad de acciones dentro de cada propuesta de cátedra para cada asignatura, devino en que estudiáramos la necesidad de clarificar de un modo concreto los abordajes de cada clase y las acciones que se iban a llevar adelante. De este modo el estudiante podría recurrir a ese elemento si no estaba conectado en el momento de la clase y así recorrer solo el camino propuesto. Se definió un modo de ventana de apertura a la clase (Fig. $3 \mathrm{La}$ ventana de apertura) por medio de un video de dos minutos que explicitara el desarrollo completo del día y aclarara los espacios que habría que visitar y los materiales a abordar.

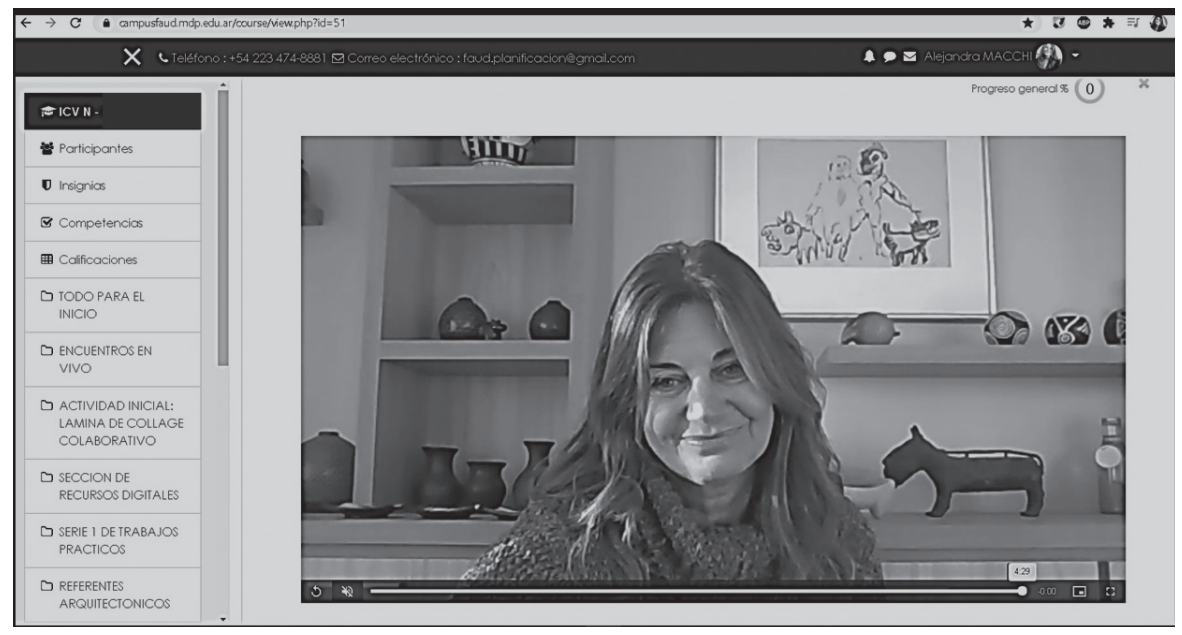

Fig 3 La ventana de apertura. Fuente propia, producción de cátedra ciclo 2020

Este inicio comentado se incorporó previo a cada horario de apertura de la clase en el Aula Virtual del Campus y se vinculó esta información en los otros espacios del taller virtual de la cátedra. 


\section{Dialéctica permanente dibujo/ maqueta}

Nuestra asignatura propone al dibujo como motor de construcción a un pensamiento geométrico sistematizado, que habilita al desarrollo de la visión espacial, geométrica y expresiva de las formas, de manera que los estudiantes puedan construir representaciones conceptuales con niveles crecientes de abstracción desde donde la geometría toma calidad de basamento del quehacer proyectual.

La experiencia virtual 2020 nos posiciono en una relación dialéctica permanente entre el dibujo y la maqueta, para los abordajes iniciales a las problemáticas formales, en función de abonar a profundizar en el control intencionado del dibujo como medio viabilizador de la concepción espacial en paralelo con un control sistemático formal a través de las maquetas.

Creemos que se introduce al estudiante al conocimiento empírico de las formas y el espacio desde operaciones abstractas que le permiten conocer sus normas y leyes de organización. Nuestro objetivo inicial se concentró entonces en operaciones con formas simples y modelos abarcables con la mirada de modo de disminuir los ocultamientos formales, muy complejos al momento de intervenir en la revisión formal generativa a través de la pantalla. (Fig. 4 M1 morfología inicial).
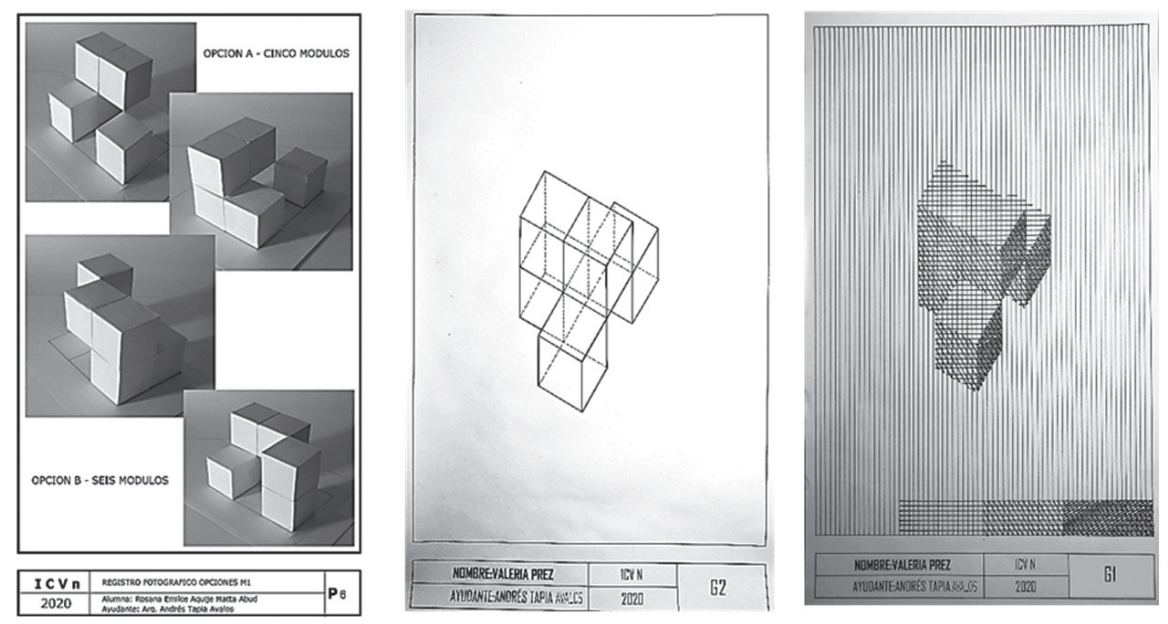

Fig4. M1 morfología inicial/ maqueta/ dibujo/Fuente propia, producción de estudiantes ciclo 2020. 
Como premisa inicial se sostuvo el objetivo de base de la asignatura donde los estudiantes se enfrenten a desarrollar hipótesis formales recurriendo progresivamente a un visón geométrico espacial en construcción, de modo de poder conformar una competencia cognitiva de aplicación directa a la resolución de los problemas de la disciplina proyectual. Los esquemas de visualización y corrección de las resoluciones formales se complementaron con videos formales de recorrido que complementaron las visualizaciones estáticas. Desde allí se especificó el tipo de toma fotográfica deseada para mostrar la morfología, aludiendo a la ubicación del observador y la angularidad respecto a sus direcciones dominantes. Esta anticipación de conceptos y elementos sistémicos ayudó conceptualmente a la comprensión del sistema gráfico geométrico a desarrollar en la aproximación práctica, produciendo imágenes y representaciones análogas, en las que se reconocen las partes y el todo, en distintos modos de aproximación y con diferentes cualificaciones. Se propuso además una puesta en escena de los objetos a registrar a través de la creación de videos tutoriales. Trabajar el fondo/ figura, las luces, la proyección de la sombra arrojada, la intensidad de la sombra propia, etc., una búsqueda de recursos para intencionar sus registros fotográficos, despegándose de la fotografía casual / cotidiana, para tener un acercamiento disciplinar a la comunicación desde la reproducción fotográfica y su participación en la comunicación virtual.

\section{Secuencias cortas / segmentación / narración}

La condición de virtualidad instrumental e inicial ineludible determinó en el curso la necesidad de abordarla desde un modo secuencial, progresivo y segmentando que en etapas previas en ciclos presenciales estaban unificadas. Se prestó especial atención a obtener la mayor precisión en la determinación de los modelos conceptuales- teóricos, formales y expresivos propuestos, con un sistema explicativo de tipo narrativo que reemplazó lo que en el taller presencial se establecían como consignas a seguir. Se desarrolla así un modelo de sinergia práctica que se mantuvo presente a lo largo de cada serie de las acciones de trabajo propuestas con los estudiantes en todo el ciclo virtual y que se caracterizó por: Un discurso explicativo escrito/ narrativo que da cuenta de los procesos previos y los futuros como modo relacional de ubicar cada acción propuesta. Abonamos a los conceptos de Matthew Lipman, filósofo y docente especializado en pedagogía cuando afirma que en el trabajo de todo pensamiento considerado complejo debe presentarse una organización basada en la coherencia y estar formado de conceptos ricos para generar un constante movimiento del pensamiento sostenido en la necesidad de investigar y explorar. 


\section{Momentos/ guía de la virtualidad operativa}

\section{Momento operacional /acción}

De corta duración está ligado a etapas iniciales de aproximación a los temas, sostenidos por medio de desarrollos abstractos: dibujos sistémicos, dibujo sobre fotos, exploraciones analógico-digitales. Los estudiantes presentan el material, lo comparten en los álbumes digitales, recorren las producciones de sus compañeros, verifican, comparan (Fig. 5 álbumes compartidos en $\mathrm{Fb}$ ). Se comienza a dar valor a los comentarios fuera de los horarios de clases y los intercambios entre ellos en sus publicaciones. El grupo de msn también cobra un rol importante en este sentido, convirtiéndose en muchas oportunidades en el espacio previo a subir la lámina al álbum, donde se comparte y se consulta. Los álbumes de $\mathrm{Fb}$ se convierten así en los pizarrones donde exponen sus trabajos con la posibilidad de la mirada constante y recurrente y el recorrido permanente.
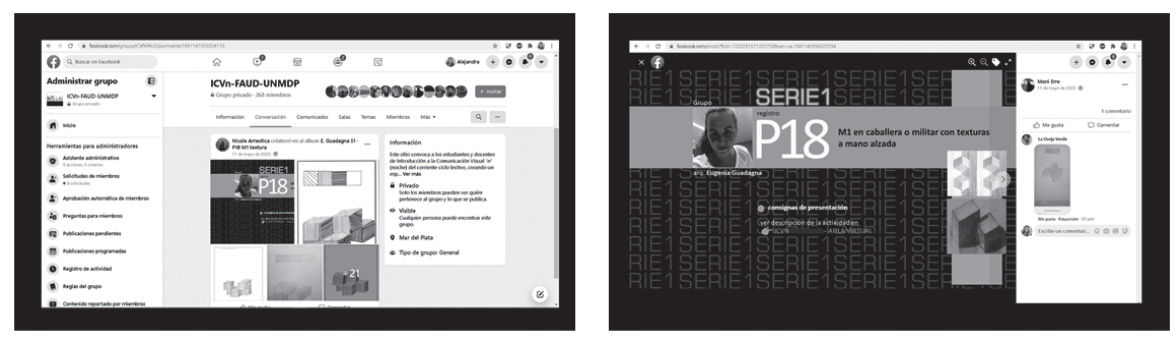

Fig 5. Álbumes compartidos en $\mathrm{Fb} /$ Recorrido virtual de imágenes, Fuente propia, producción de cátedra ciclo 2020.

\section{Momento de articulación/reflexión}

De mayor duración ubica a los estudiantes en la coyuntura del problema morfológico propuesto como articuladores de sus propios medios de solución. Están comprometidos con el conocimiento devenido en las experimentaciones morfológicas. Los docentes proponen acciones dentro de marcos referenciales con delimitaciones claras que ayudan a que cada estudiante pueda alcanzar una rápida conceptualización geométrica del problema propuesto para poder operarlo morfológicamente y enunciarlo desde una propuesta propia. Las acciones se desarrollan a través del dibujo digital colaborativo en pantalla entre docentes y estudiantes sobre los avances morfológicos producidos (Fig. 6 a, b y c Pantallas de dibujo colaborativo). 

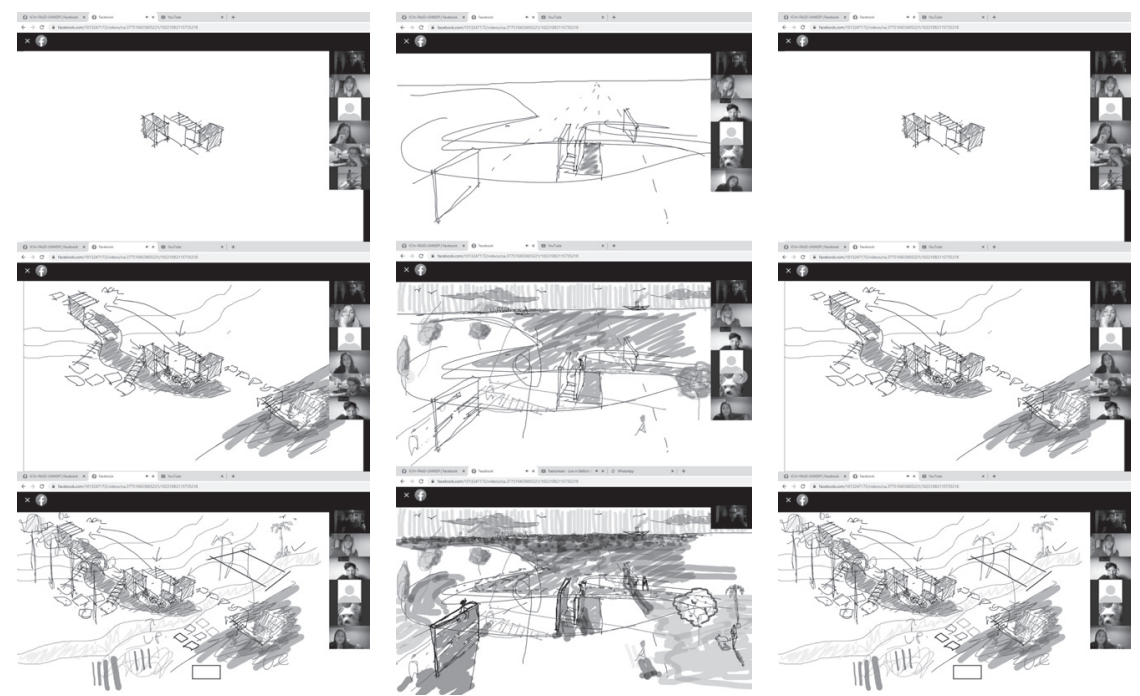

Fig. 6 a, b y c. Secuencia de pantallas de dibujo colaborativo.

Fuente propia. Desarrollo entre docentes y estudiantes del ciclo 2020.

El dibujo colaborativo se desarrolla base de un dibujo o registro subido al álbum de intercambio o por un estudiante directamente desde una pizarra virtual. Para los dos casos nos pareció importante utilizar las herramientas de dibujo del programa o aplicación en el que se está llevando adelante la videoconferencia (zoom). Esto posibilita que docentes y estudiantes cuenten con las mismas herramientas digitales de dibujo/ representación, posibilitando un intercambio fluido e incluso un soporte instantáneo en su manejo. Para el caso del dibujo colaborativo sobre un dibujo o registro, la estrategia pedagógica puede variar dependiendo el momento o los objetivos particulares de la clase. Dibujar sobre el dibujo del estudiante es un recurso rápido para clarificar conceptos sistémicos, de precisión y aspectos perceptivos, no es invasivo o irrespetuoso, se borra al instante y el dibujo original permanece. El registro de este proceso de intercambio se da por la posibilidad de grabar la clase y de construir un documento multimedial que es compartido con el grupo sobre el final de la clase, para su posterior revisión, dándole la posibilidad a quienes no han podido conectarse o hayan tenido problemas de conexión poder rever el encuentro. También los mismos estudiantes pueden tomar capturas de pantalla de las observaciones a modo de apunte, congelando momentos de la clase que a ellos les parecieron importantes. Para la modalidad de dibujo colaborativo sobre pizarra virtual, se pueden elaborar estrategias diversas, como la explicación de consignas específicas de parte del docente, donde se acompaña el discurso con dibujos conceptuales y se abre al intercambio cuando el do- 
cente invita a los estudiantes a dibujar sobre la pizarra, estas secuencias pueden ayudar a fomentar la comunicación mediante representaciones sintéticas.

Que los estudiantes configuren nuevas y propias ideas de aproximación a las formas espaciales los aproxima a la comprensión de la problemática de la arquitectura. Esta es una base argumental para el uso de los medios de representación que permite un primer nivel de conceptualización de los problemas formales, entendiendo que la geometría nos capacita para poder incidir en el espacio, resolviendo todo tipo de situaciones cada vez con mayor complejidad.

\title{
Un pensamiento motivado o como dibujar en el aire
}

\begin{abstract}
¿Son ustedes conscientes de la universalidad de dibujar en el aire? Desde el primer momento de su factura a través de los nuevos medios, nuestros dibujos y nuestras palabras escritas, son capaces de cruzar en un segundo el mundo entero.(...) es esa universalidad, real, palpable, eficaz, lo que me fascina (Campos Baeza., 2017, p.85).
\end{abstract}

Nos propusimos desagregar, identificar, valorar y repensar aquellos aspectos pedagógicos más relevantes que dentro del espectro de la propuesta pedagógica para Comunicación Visual en el Ciclo Introductorio a la carrera de Arquitectura fuimos construyendo en el contexto de la pandemia en el ciclo 2020. Este abordaje analítico expone además de los caminos didácticos que se abordaron en un momento de intensa productividad y creatividad docente, un marco ideológico que nos sostiene como cátedra y que continúa nutriendo y dirigiendo sus procesos de construcción de conocimiento, conformándose en un corpus que actúa no solo como guía pedagógica sino además como postura ideológica integral.

Seguimos así confirmando y conformando también en nosotros un perfil particular a nuestro accionar educativo vinculado a otras áreas fuera del claustro universitario. Esta mirada sobre nosotros mismos en función a los cambios que nos atraviesan como sociedad y como institución la resignificamos desde una respuesta prioritaria: la de la calidad educativa. Ese posicionamiento situado permanentemente en el aquí y ahora, es el que ha orientado a la cátedra a buscar y proveer al estudiante en este nuevo contexto, de las capacidades y herramientas disciplinares y conceptuales necesarias que contribuyan a su formación como individuos capaces de seguir mejorando por sí mismos e insertándose en el tejido social contemporáneo como factores de superación. Entendemos de este modo que se puede seguir profundizando en el estímulo y desarrollo de lógicas de pensamiento analógico digitales, como complementarias y enriquecedoras. Se trasciende el dominio de un software, se abona a la construcción de un maridaje cognitivo que consolida la idea de una propuesta donde la construcción y el desarrollo del pensamiento geométrico espacial se argumenta explorando las posibilidades y potencialidades del medio digital, operando en los nuevos contextos de simultaneidad, fluidez y superposición impuestos por el paradigma tecnológico actual. 


\title{
Listado de Referencia Bibliográfica
}

Campos Baeza, A. (2017). Pensar con las manos. Buenos Aires: Ed. Nobuko.

Han, B.C. (2015). La salvación de lo bello. Barcelona: Herder.

Litwin, E. (2007). Reflexiones en torno a una didáctica para la enseñanza proyectual. En

Mazzeo, C. y Romano, A. M. (2007). La enseñanza de las disciplinas proyectuales. Buenos Aires: Ed. Nobuko.

Moisset, I. (2003). Fractales y formas arquitectónicas. Córdoba: i+p.

Morin, E. (2003). Introducción al pensamiento complejo. Barcelona: Gedisa.

Sztulwark, P. (2015). Componerse con el mundo. C.A. Buenos Aires, Argentina: Diseño.

\begin{abstract}
We introduce our students to visual communication in architecture understanding that initiality in the context of the discipline. We reflect from an existence fed by a visuality that permanently organizes our ways of life and interaction with the environment. A new system of the visible demanded by virtuality, reconditioned the logics of understanding and analysis of the world, installing us in a new way of seeing and relating our gaze to our actions. The proposal for the chair was to articulate this new visibility in the cycle 2020. We required analysis, exploration and articulation between different, but not conflicting, knowledge. We chose to take action and we were surprised by the knowledge.
\end{abstract}

Keywords: communication - visuality - articulation-coding - virtuality.

Resumo: Apresentamos nossos alunos à comunicação visual em arquitetura, entendendo essa inicialidade no contexto da disciplina. Refletimos a partir de uma existência alimentada por uma visualidade que organiza permanentemente nossos modos de vida e interação com o meio ambiente. Um novo sistema do visível exigido pela virtualidade, recondicionou as lógicas de compreensão e análise do mundo, instalando-nos numa nova forma de ver e relacionar o nosso olhar com as nossas ações. A proposta da cadeira era articular esta nova visibilidade no ciclo 2020. Exigimos análise, exploração e articulação entre conhecimentos diferentes, mas não conflituosos. Optamos por agir e ficamos surpresos com o conhecimento.

Palavras chave: comunicação - visualidade - articulação-codificação - virtualidade.

[Las traducciones de los abstracts fueron supervisadas por el autor de cada artículo] 